\title{
A IMPORTÂNCIA DO EXAME CITOPATOLÓGICO NA PREVENÇÃO DO CÂNCER DO COLO UTERINO
}

Temilde Lourdes da Silva Santos ${ }^{1}$, Murilo Barros Silveira², Hânstter Hállison Alves Rezende ${ }^{3}$

${ }^{1}$ Enfermeira, Especialista em Saúde Pública do Cais Nova Era, Aparecida de Goiânia-GO, Brasil.

2 Biomédico (TAE), Mestrando em Biologia da Relação Parasito-Hospedeiro do Instituto de Patologia Tropical e Saúde Pública da Universidade Federal de Goiás, Goiânia-GO, Brasil. (murilo_bsilveira@hotmail.com)

3 Professor do curso de Biomedicina, Unidade Acadêmica Especial de Ciências da

Saúde, Regional Jataí, Universidade Federal de Goiás-UFG, Jataí-GO, Brasil.

\section{Recebido em: 06/04/2019 - Aprovado em: 10/06/2019 - Publicado em: 30/06/2019 DOI: 10.18677/EnciBio_2019A151}

O câncer de colo uterino acomete principalmente mulheres na idade reprodutiva, principalmente e constitui grave problema de saúde pública, devido ao alto índice de mortalidade, provocada pelo diagnóstico tardio. O objetivo geral deste estudo é abordar sobre a importância do exame citopatológico (teste de Papanicolau) para a prevenção do câncer de colo uterino. O estudo foi conduzido por meio de pesquisa bibliográfica, com material encontrado nas bases de dados da Biblioteca Virtual de Saúde, totalizando 20 artigos, publicados entre 2012 e 2017, em língua portuguesa; na íntegra; disponíveis; e diretamente relacionados ao tema. A leitura e análise dos artigos mostraram que o conhecimento das mulheres brasileiras sobre a prevenção do câncer de colo uterino é baixo e está relacionado com a situação sociodemográfica, econômica e cultural. A Atenção Primária à Saúde oferece o exame citopatológico de forma gratuita, mas nem sempre consegue a adesão das mulheres, sendo relevantes as crenças e mitos sobre o câncer de colo uterino e o exame preventivo. Assim, o enfermeiro tem importante papel junto a essa população, principalmente no que se refere à educação em saúde, de forma a mudar conceitos e conseguir ampla cobertura para a realização da prevenção. $O$ enfermeiro precisa aliar o conhecimento à prática, ter estrutura física, organização de trabalho adequada e oferecer atendimento humanizado às mulheres, sendo o acolhimento e a informação as principais estratégias de abordagem, de forma a obter adesão plena ao exame preventivo do câncer de colo uterino.

PALAVRAS-CHAVE: Atenção Primária à Saúde, Câncer de colo uterino, Exame citopatológico. 


\title{
THE IMPORTANCE OF THE CYTOPATHOLOGICAL EXAMINATION IN THE PREVENTION CANCER OF THE UTERINE COLUMN
}

\begin{abstract}
Cervical cancer mainly affects women of reproductive age, and is a serious public health problem due to the high mortality rate caused by late diagnosis. The general objective of this study is to discuss the importance of cytopathological examination (Pap smear test) for the prevention of cervical cancer. The study was conducted through a bibliographical research, with material found in the databases of the Virtual Health Library, totaling 20 articles, published between 2012 and 2017, in Portuguese; in full; available; and directly related to the theme. The reading and analysis of the articles showed that the knowledge of Brazilian women about the prevention of cervical cancer is low and is related to the sociodemographic, economic and cultural situation. Primary Health Care offers the cytopathological examination free of charge, but it doesn't always achieve women's adherence, and the beliefs and myths about cervical cancer and the preventive examination are relevant. Thus, nurses play an important role in this population, especially in health education, in order to change concepts and achieve broad coverage for prevention. The nurse needs to combine knowledge with practice, have a physical structure, adequate work organization and offer humanized care to women, with the host and information being the main strategies to approach, in order to obtain full adherence to the cervical cancer preventive examination.
\end{abstract}

KEYWORDS: Primary Health Care, cancer of the uterine cervix, cytopathological examination.

\section{INTRODUÇÃO}

O colo uterino ou cérvix é a parte mais distal e constrita do útero, projetandose através da parede vaginal anterior, apresentando um formato de cone, com o ápice geralmente voltado para a parede vaginal posterior. Nessa região pode se desenvolver uma neoplasia envolvendo diversas anormalidades celulares epiteliais, tendo seu início como lesões intraepiteliais e culminando ao câncer. Essa neoplasia é causada pelo Human Papiloma Virus, o HPV, presente na pele e mucosas, sendo transmitido preferencialmente por via sexual (MARQUES et al., 2007).

Além da infecção pelo HPV, outros fatores de risco para o câncer de colo uterino são a idade precoce da primeira relação sexual; número de parceiros sexuais; parceiros promíscuos; má nutrição; número de gravidezes da mulher; tabagismo; uso de contraceptivos orais; baixo nível socioeconômico e possível estado de imunossupressão da paciente, visto que a baixa imunidade retarda 0 reconhecimento do HPV pelo sistema imunológico. A deficiência dos antígenos não oferece resposta adequada ao ataque do HPV, sendo que a paciente fica predisposta ao desenvolvimento de tumores, cujo tratamento pode ser mais difícil, com maior número de recidivas e com lesões mais exuberantes (LEON et al., 2016).

O câncer de colo de útero ocupa, no mundo, o segundo lugar no ranking dos cânceres femininos, só perdendo para a neoplasia mamária. No Brasil, está em terceiro lugar, segundo dados do Instituto Nacional de Câncer José Alencar Gomes da Silva (INCA), em 2014, com taxa de incidência de 15 novos casos em 100.000 mulheres ao ano. A doença é pouco frequente antes dos 30 anos, com maior incidência entre 40 e 60 anos de idade (SILVA et al., 2016). No estágio inicial, o câncer de colo uterino é geralmente assintomático, pois a doença evolui de forma 
lenta, desde fases pré-clínicas, detectáveis e curáveis, até a fase metastática, que ocorre em grande parte dos diagnósticos. Seu potencial de prevenção e cura é alto, desde que o diagnóstico seja precoce, sendo que a faixa etária mais apropriada para esse procedimento fica em torno de 20 a 29 anos de idade (CASARIN; PICCOLI, 2011).

O diagnóstico do câncer de colo uterino inclui anamnese, exame físico, testes laboratoriais e imagens radiográficas, principalmente a ressonância magnética (IRM), cuja sensibilidade pode definir melhor o tamanho do tumor e sua extensão. A tomografia por emissão de pósitrons (PET) serve para determinar o grau de envolvimento dos linfonodos na lesão. A remoção de lesões pré-invasivas é feita com base no exame citopatológico, com encaminhamento para colposcopia e biópsia dirigida se for detectada alguma alteração do esfregaço. $O$ exame citopatológico é utilizado no Brasil como forma de prevenção do câncer de colo uterino (BRASIL, 2013).

O exame citopatológico é um teste de citologia oncótica de colo uterino e é considerado 0 melhor procedimento para detectar as primeiras lesões que aparecem, devendo ser realizado de forma rotineira pelas mulheres entre 25 e 64 anos de idade. Contudo, fatores sociais, econômicos e comportamentais fazem com que a adesão ao exame não seja plena, o que diminui os indicadores de sobrevida quando a doença é diagnosticada já em estágio avançado (SILVA et al., 2015).

O exame citopatológico é oferecido pelo Sistema Único de Saúde (SUS), como parte da Atenção Primária à Saúde (APS) e das políticas de saúde da mulher, para realizar o rastreamento, o diagnóstico e o tratamento do câncer de colo uterino. Nas Unidades Básicas de Saúde (UBS) os enfermeiros identificam as mulheres elegíveis para a realização do exame, por meio de protocolos de priorização de usuárias, e buscam aquelas que não comparecem, oferecendo suporte e informação. Isso tem feito com que o número de exames tenha aumentado em pelo menos cinco pontos percentuais. O nível dos serviços oferecidos pelas UBS é fundamental para a adesão à realização do exame, principalmente em colaboração com a Estratégia Saúde da Família, cujos profissionais estão mais próximos das mulheres (TOMASI et al., 2015).

O grau das lesões que podem ser evidenciadas pelo exame citopatológico é variado, desde alterações celulares de natureza benigna, até atipias celulares, classificadas como escamosas, glandulares ou de origem indefinida, que podem ser neoplásicas ou não. As células escamosas podem significar uma lesão intra-epitelial de baixo grau, lesão intraepitelial de alto grau ou o estágio invasor do câncer de colo uterino. As pacientes com esses dois últimos tipos de lesões devem ser encaminhadas pela Atenção Básica para Unidades de Referência de Média Complexidade, para realizarem imediatamente uma colposcopia, exame do colo uterino, feito pelo ginecologista, usando um colposcópio, que aumenta a visibilidade e soluções para corar as células atacadas pelo HPV (SIQUEIRA et al., 2014).

Os exames, bem como a cirurgia, permitem o estadiamento do câncer de colo uterino, cujos parâmetros foram estabelecidos pela Federação Internacional de Ginecologia e Obstetrícia (FIGO). No estádio IA1 ocorre a invasão do estroma; o estádio II, dividido em duas fases, é caracterizado pelo envolvimento da vagina na lesão, na fase IIA. Na fase IIB os paramétrios podem ser invadidos, mas a parede pélvica ainda não é atingida. No estádio IIIA as lesões invadem o terço inferior da vagina, mas não atingem a parede pélvica, causando hidronefrose, prejudicando o funcionamento renal. No estádio IVA as lesões podem invadir a mucosa da bexiga, o 
reto e irem além da pelve verdadeira. No estádio IVB ocorrem metástases à distância. $O$ estadiamento é importante para definir o tratamento, que pode ser feito mediante cirurgia (conização ou histerectomia), quimioterapia e radioterapia (SOUZA et al., 2013).

Para prevenir a infecção pelo HPV, que é a principal causa do câncer de colo uterino, o Ministério da Saúde disponibiliza dois tipos de vacinas: a quadrilavente (HPV4) e a vacina contra o HPV oncogênico (HPV2), que são produzidas por meio da técnica de DNA recombinante, criando a proteína $L 1$, que compõe o capsídeo do HPV. A vacina permite a formação de anticorpos neutralizantes em títulos altos, que protegem contra a neoplasia uterina, sendo que a HPV4 é indicada para homens e mulheres, dos nove aos 26 anos de idade, administrada em intervalos de 0, 2 e 6 meses (MELLO, 2013).

A vacina HPV2 é indicada para mulheres entre 10 e 25 anos de idade, sendo administrada em intervalos de 0, 1 e 6 meses. A idade ideal para receber a vacina fica entre 11 e 12 anos, para que a proteção se efetive antes do início da vida sexual e de possível exposição ao vírus. Gestantes e pessoas alérgicas não podem ser vacinadas contra o HPV (MELLO, 2013).

Dessa forma, o objetivo geral do presente estudo é abordar sobre a importância do exame citopatológico para a prevenção do câncer de colo uterino, avaliando os fatores de risco, etiologia e epidemiologia do câncer de colo uterino; e levantar a discussão sobre a importância das ações da Atenção Primária à Saúde (APS) na adesão de todas as mulheres na faixa etária da prevenção do câncer de colo uterino para a realização do exame.

\section{MATERIAL E MÉTODOS}

Trata-se de uma revisão da literatura, realizada a partir de seleção de artigos científicos que abordam o que já foi publicado sobre as ações que podem ser desenvolvidas na atenção primária, no sentido de abordar sobre a importância da realização do exame citopatológico para a prevenção do câncer de colo uterino.

Uma vez definido o tema, foi acessada a Biblioteca Virtual em Saúde (BVS), além do Google Acadêmico e Google Books, para a busca dos textos adequados à pesquisa. Foram utilizados os descritores: Atenção Primária à saúde; Neoplasias do colo do útero e Teste de Papanicolau, conforme constam nos Descritores de Ciências da Saúde (Decs), versão 2017. Em seguida, procedeu-se à busca de textos, levando-se em consideração os seguintes critérios de inclusão: texto completo e disponível; publicação em português; publicação entre 2012 e 2017, com exceção de documentos publicados pelo Ministério da Saúde; e relevância em relação ao tema abordado. Os critérios de exclusão foram: texto incompleto ou não disponível; publicação em idioma que não seja o Português; publicação anterior ao período selecionado; e não apresentar relação direta com o tema abordado. A busca foi realizada entre 1 e 15 de outubro de 2017.

\section{RESULTADOS E DISCUSSÃO}

Foram localizados 52 artigos que atendiam aos critérios de inclusão. Após leitura sistemática, iniciou-se a leitura interpretativa do material encontrado, quando foram lidas em profundidade a introdução, a discussão e a conclusão de cada texto, no sentido de verificar a perfeita adequação ao tema, com anotações que consideravam o problema da pesquisa, ressalvando às ideias principais e dados 
mais importantes que os autores relacionaram na conclusão, assim foi selecionado 20 artigos.

O câncer de colo uterino é a principal causa de morte por câncer entre as mulheres de países em desenvolvimento, chegando a $85 \%$ dos óbitos, principalmente na faixa etária de 45 a 49 anos, a fase de maior risco. Para evitar que isso aconteça é preciso diagnosticar a doença precocemente e, nesse aspecto, o exame citopatológico tem demonstrado ser uma estratégia efetiva, proporcionando até $100 \%$ de cura, nos estágios iniciais. Este exame foi introduzido no Brasil na década de 1940, mas foi institucionalizado somente entre 1986 e 1987, por meio de ações do Ministério da Saúde, com a realização de pelo menos 13 milhões de exames/ano (FREITAS et al., 2012).

Uma pesquisa realizada no estado do Espírito Santo mostrou que a média de idade das pacientes era de 53,8 anos no momento do diagnóstico. As mulheres de cor não branca, baixa escolaridade, casadas, com encaminhamento do SUS e provenientes do maior centro urbano da região (Vitória) eram a maioria. O tipo histológico predominante foi o carcinoma de células escamosas (87\%) e os estadiamentos com maior número de casos foram o III (44\%) e o II (31,4\%). 28,2\% das mulheres tiveram recidiva local e 43,4\% tiveram metástases à distância. As variáveis sociodemográficas são importantes para definir o grupo de mulheres mais afetadas pelo câncer de colo uterino, além das dificuldades de acesso ao sistema público de saúde (MASCARELLO et al., 2012).

O Brasil ainda não realiza triagem adequada do câncer de colo uterino, de forma organizada e periódica. A realização do exame citopatológico é mais ocasional e oportunística, devido à falta de informação, por parte das mulheres e de estratégias efetivas e humanizadas, por parte do sistema público de saúde. A não adesão ao exame é encontrada principalmente entre as mulheres com baixa escolaridade. Geralmente, deixam para realizar o exame de três em três anos, deixando de fazê-lo anualmente. Outras o realizam com menos de um ano de intervalo. O exame só pode ser trianual se em dois exames consecutivos anuais 0 resultado for negativo. Assim, o intervalo ideal é de um ano. Os principais motivos para a não realização do exame são a falta de tempo e a vergonha demonstrada diante dos profissionais de saúde, especialmente quando são homens (SOUZA et al., 2013).

Um estudo realizado em Mirandópolis, no interior do estado de São Paulo, traz algumas contribuições acerca do que pensam as mulheres durante a realização do exame citopatológico: em $41 \%$ dos casos os profissionais de saúde não explicam o procedimento a ser realizado ou o fazem de maneira superficial, o que aumenta a sensação de medo e vulnerabilidade em cerca de $60 \%$ das mulheres que se submetem ao exame pela primeira vez; $33 \%$ das mulheres não têm preferência pelo sexo de quem faz o exame, mas $49 \%$ gostariam de serem atendidas por profissionais do sexo feminino, para terem mais confiança e menos constrangimento. Como a não adesão ao exame está ligada também aos fatores psicológicos, como crenças, atender as mulheres com profissionais do sexo feminino é uma questão a ser considerada pelo sistema público de saúde (SOUZA et al., 2013).

No interior do estado de Goiás, na cidade de Anápolis, a faixa etária que mais realiza o exame citopatológico é de 26 a 45 anos, estando o grupo em idade reprodutiva. O nível de escolaridade das mulheres foi um pouco mais elevado do que em outros lugares do Brasil, com 47,5\% apresentando o Ensino Médio, 
predominantemente da zona urbana, com nível muito baixo de fumantes, casadas e com renda entre um e dois salários mínimos (MATIAS et al., 2015).

Neste mesmo estudo realizado na cidade de Anápolis, $91 \%$ das mulheres conheciam a finalidade do exame, mas o índice de desconforto ainda é alto $(61,6 \%)$. A periodicidade na realização do exame variou muito, revelando falta de informação pelas pacientes. Algumas infecções vaginais foram detectadas, mas nenhum caso de câncer de colo uterino, o que demonstra a associação entre nível de escolaridade e realização da prevenção. Nessa região o médico é quem mais divulga a importância do exame citopatológico, mostrando baixa eficiência das campanhas, o que pode ser constatado em outros locais do país (MATIAS et al., 2015).

Enquanto as mulheres da zona urbana e com maior escolaridade possuem mais conhecimentos sobre o exame citopatológico, as mulheres da zona rural, com baixa escolaridade, apresentam uma compreensão menor ou equivocada sobre a sua realização, dirigindo-se ao sistema público de saúde apenas quando manifestavam sinais clínicos do câncer de colo uterino, descaracterizando, dessa forma, a prevenção. Em um estudo realizado no interior do estado do Piauí, as pacientes não tinham o conhecimento sobre a periodicidade do exame, mostrando a necessidade de planejamento e promoção da prevenção pelas equipes de saúde locais. Além disso, só conseguiam realizar o exame na cidade mais próxima, o que implica em custos e as equipes de saúde não atendem continuamente na zona rural, dificultando 0 acesso até mesmo às consultas. Portanto, fatores geográficos constituem impedimentos na realização do exame (CARVALHO et al., 2016).

$A$ idade em que a mulher se encontra no momento do exame também é fator importante. Nesse sentido, uma pesquisa realizada na periferia da cidade de Fortaleza, capital do estado do Ceará, mostrou que as adolescentes apresentaram o maior grau de inadequabilidade, tanto no que se refere à atitude, quanto na parte prática, com conhecimentos inadequados sobre as razões para realizar o exame e a maioria estava fazendo pela primeira vez. Além disso, não retornam para receber os resultados e comparecer às consultas (SILVEIRA et al., 2016).

O conhecimento sobre a importância do exame citopatológico aumenta com o avançar da idade, tendo o melhor resultado em mulheres jovens. As adolescentes, que geralmente começam a vida sexual muito cedo, com multiplicidade de parceiros, estão expostas aos fatores de risco do câncer de colo uterino, sem que tenham conhecimentos adequados sobre a doença e não tenham o hábito de colocar em prática o exame e as consultas de apresentação dos resultados. A escola, onde se encontra boa parte dessa população, poderia ser acionada com mais ênfase como instância educativa, mas não deixando de lado as ações dos serviços de saúde, principalmente a busca ativa das adolescentes, para incluí-las nas campanhas de vacinação contra o HPV (SILVEIRA et al., 2016).

O nível educacional da população e a renda per capita são utilizados para compor o Índice de Desenvolvimento Humano (IDH), que mostra ter relação com a ocorrência do câncer de colo uterino. Um estudo no Vale do Ribeira (região entre o sudeste paulista e o estado do Paraná), com 30 cidades, avaliou a frequência das lesões encontradas em exames citopatológicos, no período de dois anos (20142015). O baixo IDH da região resultou em baixa adesão ao rastreamento precoce da doença. As lesões de alto grau (carcinoma e adenocarcinoma) foram detectadas em $0,05 \%$ e $0,01 \%$, respectivamente. A maioria das mulheres estava na faixa preconizada pelo Ministério da Saúde (25-64 anos) (ETLINGER-COLONELLI; LORENTE, 2016). 
Nesta pesquisa nenhuma adolescente apresentou carcinoma ou adenocarcinoma, mas ocorreram casos de lesões de alto grau ou suspeitas. Mulheres com mais de 65 anos também apresentaram anormalidades, além de um caso de carcinoma, sendo que a maior parte das ocorrências desse tipo histológico ocorreu na faixa de 25 a 34 anos. Devido ao tratamento, essas mulheres, que estavam na idade reprodutiva, poderiam ficar sujeitas a terem partos prematuros, no caso de novas gestações. A região onde vivem, com baixo IDH, necessita de mais assistência no rastreamento do câncer de colo uterino. Ações educativas necessitam ser feitas, para aumentar o conhecimento das mulheres sobre o exame preventivo e sobre o seguimento, para aquelas que forem diagnosticadas com algum tipo de lesão (ETLINGER-COLONELLI; LORENTE, 2016).

Grande parte dos exames citopatológicos é realizada de forma oportunística e o prénatal constitui uma oportunidade. No entanto, as vezes essa oportunidade é perdida. Foi o caso de mulheres mais jovens, solteiras, de baixa escolaridade, não brancas e de baixa renda, chegando a $21,4 \%$ em cidade do interior do estado de Minas Gerais, com filhos menores de dois anos de idade. Elas haviam feito o prénatal, mas relataram falta de conhecimentos sobre o exame, não adesão por se sentirem saudáveis e dificuldades para marcar a consulta e realizá-lo. A par disso, é preciso constatar a falta de encaminhamento por parte dos serviços de saúde, perdendo-se a oportunidade para ampla cobertura em relação ao exame citopatológico, aumentando o desafio para o controle do câncer de colo uterino (RIBEIRO et al., 2016).

Mulheres com filhos também demonstraram baixo conhecimento sobre 0 exame preventivo em Feira de Santana, estado da Bahia, com 12,6\% de não adesão. As mulheres que apresentavam idade mais elevada na faixa recomendada, de cor preta ou parda, baixa escolaridade, sem parceiro fixo, de baixa renda, que não usavam métodos contraceptivos e já haviam apresentado DST's foram as que menos aderiram ao exame ou nunca o realizaram, nem mesmo no pré-natal. Ainda que a cobertura total tenha sido considerada boa, os casos apresentados mostraram que eram necessárias ações nos serviços públicos de saúde locais, para que as mulheres com elevados fatores de risco não ficassem sem realizar o exame citopatológico, considerando-se o pré-natal como oportunidade (ANDRADE et al., 2014).

Em uma Unidade Básica de Saúde (UBS) localizada em Londrina, no estado do Paraná, a coleta de material para a realização do exame citopatológico não é oportunística. Duas vezes por semana a equipe de saúde disponibiliza 64 vagas para as moradoras da região, num dia pela manhã e no outro à tarde, para atender a todas. Além da demanda espontânea, as mulheres que procuram por outros atendimentos também são captadas. As faltas, motivadas principalmente por crenças errôneas sobre o exame, são anotadas no prontuário, 100\% das mulheres pesquisadas já haviam realizado o exame anteriormente e a principal razão para essa adesão foi a organização do serviço e a presença de profissionais qualificados e do sexo feminino (SILVA et al., 2015).

Cerca de $24 \%$ das mulheres que participaram da pesquisa citada mencionaram dificuldades com o horário de atendimento, mas como foi mencionado, são dois horários diferentes, exatamente para atender a demanda. Contudo, o medo, o constrangimento e vergonha, aliados à coincidência com o ciclo menstrual fizeram com que muitas mulheres faltassem ao exame agendado. O que se observa, portanto, é a organização da equipe frente ao descuido das mulheres com a própria 
saúde, resultado de atitudes e crenças errôneas e até mesmo falta de tempo, como foi alegado por várias delas (SILVA et al., 2015).

Os mesmos motivos também foram encontrados em pesquisa realizada no interior do estado de Pernambuco, em UBS. As mulheres tinham consciência da importância do exame, contudo $38 \%$ alegaram crenças familiares rigorosas, que as impediam de realiza-lo, mesmo correndo o risco de terem câncer de colo uterino. Eram mulheres jovens, que alegaram como motivos para não realizarem o exame a vergonha, dor, internação, ciclo menstrual, esquecimento, falta de parceiro sexual, falta de tempo e realização do exame em serviço particular. A UBS localizava-se próxima às residências e o relacionamento com os profissionais de saúde era considerado positivo (SILVA et al., 2016).

As mulheres que se consideram saudáveis também devem realizar o exame citopatológico, pois a fase inicial do câncer de colo uterino é assintomática. Esse foi o caso de $25,6 \%$ das mulheres pesquisadas em Pernambuco, que se consideravam com boa saúde, não realizando o exame. Aquelas que eram solteiras e não possuíam parceiros fixos, constituíam grupo de risco, devido à possibilidade de contraírem HPV. Nem sempre essas mulheres usavam preservativo nas relações sexuais. O fato de não realizarem os exames periodicamente demonstram a necessidade de ações educativas, para fixar o conhecimento sobre os fatores de risco para o câncer de colo uterino e a importância da prevenção (SILVA et al., 2016).

No interior do estado da Paraíba mulheres jovens, a maioria agricultoras ou donas de casa, também alegaram motivos semelhantes, mas com um agravante: o desinteresse na prevenção de doenças cérvico-vaginais, além do medo de contraírem doenças por meio do exame. Eram mulheres com baixo nível de escolaridade e renda, que não sabiam como era realizado o exame, demonstrando a falta de informações. A maioria não conhecia os fatores de risco para o aparecimento do câncer de colo uterino. Esse cenário implica em maior atuação dos serviços públicos de saúde, no sentido de esclarecer a população feminina sobre a importância da prevenção e como o exame é realizado, oferecendo acolhimento para aquelas mulheres que se sentirem constrangidas e com medo (LIMA et al., 2017).

A vigilância em saúde destinada à cobertura do exame citopatológico está relacionada à prevenção primária, com ações de promoção e proteção e à prevenção secundária, com ações específicas para o rastreamento do câncer de colo uterino. A educação em saúde é a principal abordagem da prevenção primária, podendo ser realizada nas consultas e visitas domiciliares, com o objetivo principal de desmistificar o exame preventivo. Essas ações devem ser desenvolvidas preferencialmente pelos agentes de saúde e enfermeiros, de forma intersetorial, com a participação de toda a comunidade. Campanhas na mídia eletrônica, como televisão e rádio; na mídia impressa, como jornais, revistas, cartazes e adesivos; ou multimodal, combinando as duas estratégias anteriores podem atingir grande número de mulheres (RODRIGUES et al., 2012).

Uma experiência conduzida nos municípios de Ceres e Santa Isabel, no estado de Goiás, usou as estratégias relacionadas à mídia impressa, além de rodas de conversa com as mulheres, no ambiente das UBS's e o tempo de um programa de rádio, para promover a educação em saúde. Nessas cidades a adesão ao exame citopatológico era baixa e um grupo de acadêmicos do curso de Medicina empreendeu esforços para mudar a situação. $O$ trabalho foi realizado em conjunto ENCICLOPÉDIA BIOSFERA, Centro Científico Conhecer - Goiânia, v.16 n.29; p. 1954 
com agentes comunitários de saúde. Foi necessário lidar com sentimentos e crenças das comunidades. O programa de rádio evidenciou os temas a serem tratados nas rodas de conversa, cujo principal resultado foi desmistificar o câncer como doença fatal, desde que a mulher realize os exames, para ter diagnóstico precoce e tratar, se for o caso (RODRIGUES et al., 2012).

O rastreamento ou prevenção secundária é representado pela captação de mulheres para a realização do exame, por meio de busca ativa e oportunidade (prénatal, realização de mamografia, controle do diabetes e da hipertensão arterial); oportunização para a coleta de material para a realização do exame, principalmente nas zonas rurais, em períodos fixos, com Unidades Móveis, para criar o hábito. As equipes de saúde devem registrar adequadamente os dados das mulheres participantes. O registro é importante para gerar relatórios, planejar novas ações, monitorar o último exame e captar as mulheres que ainda não estejam inseridas nos programas de prevenção do câncer de colo uterino e se for computadorizado tornase mais eficaz (RIBEIRO; ANDRADE, 2016).

No Ministério da Saúde funciona o Sistema de Informação do Câncer do Colo do Útero (SISCOLO), que gerencia e monitora as ações do programa Viva Mulher: Programa Nacional de Controle do Câncer do Colo do Útero, que alcança todo o Brasil desde 1997. Em Minas Gerais, os dados do SISCOLO permitiram avaliar a cobertura do exame citopatológico nas macrorregiões do estado. No ano 2000, em relação aos quase 2 milhões de exames programados pelo SUS, a melhor cobertura estava nas macrorregiões Triângulo do Norte, Triângulo do Sul e Centro e as piores foram em Jequitinhonha, Nordeste e Leste do Norte. Em termos percentuais a cobertura foi de $63,8 \%$. Como as mulheres nem sempre fazem o exame na rede pública de saúde, a cobertura populacional chegou a 66,4\% (NASCIMENTO et al., 2015).

Em 2010 a meta do SUS estava em torno de um milhão e quatrocentos mil exames, sendo que a cobertura efetiva foi de $89,3 \%$ e de $95,4 \%$ pela meta populacional. Na meta do SUS, as macrorregiões Nordeste, Jequitinhonha e Sul apresentaram as maiores coberturas, recuperando o mau resultado de uma década, mas Jequitinhonha continuou abaixo da meta populacional. A região é pobre e depende essencialmente dos serviços públicos de saúde. Nas demais macrorregiões houve aumento da cobertura em relação à meta do SUS, mas nem sempre em relação à meta populacional. O ano de 2002 foi o único em que as duas metas se aproximaram. Mesmo com os dados do SISCOLO não é fácil estimar a cobertura real, pois a metodologia utilizada pelo Sistema de Informações de Atenção Básica (SIAB) é diferente daquela usada pelo Instituto Brasileiro de Geografia e Estatística (IBGE) para recensear a população (NASCIMENTO et al., 2015).

Ainda em relação ao estado de Minas Gerais, foram detectadas diferenças regionais na implementação das políticas públicas de saúde. Existe grande rotatividade nas equipes da Estratégia Saúde da Família nos municípios, não permitindo a formação de vínculos com a comunidade e interferindo na dinâmica do trabalho. Nas regiões pobres a falta de escolaridade diminui o acesso das mulheres à informação, fazendo com que as mulheres não se cuidem. Além disso, alegam dificuldades para agendar as consultas e falta de treinamento dos profissionais da Atenção Básica a realização do exame citopatológico. A pesquisa realizada sugeriu abordar a cobertura pelo ângulo populacional, visto que pode oferecer melhor visão sobre a real quantidade de exames realizados em determinada região (NASCIMENTO et al., 2015). 
A qualidade dos laboratórios que processam os exames citopatológicos precisa ser avaliada, o que pode também ser feito com dados fornecidos pelo SISCOLO. A aplicação do método citopatológico é subjetiva, depende da experiência do profissional que o executa e das condições de trabalho. No Brasil, os profissionais possuem perfis muito variados e as condições de trabalho nem sempre são adequadas. Isso pode interferir nos resultados, maximizando a ocorrência de erros diagnósticos. O controle de qualidade é avaliado internamente e externamente. No que se refere à qualidade interna, a pesquisa, relativa ao ano de 2010 e válida para todo o Brasil, avaliou aspectos como Índice de Positividade (IP) e os percentuais das alterações encontradas, conforme o tipo histológico. Agentes internos avaliaram a qualidade (BORTOLON et al., 2012).

No que se refere à qualidade externa, a avaliação é feita por agentes externos ao laboratório. No ano de 2010 um percentual de 99\% dos exames realizados no Brasil foi considerado satisfatório. Laboratórios com IP superiores a $10 \%$ devem ser reavaliados, pois podem apresentar viés de seleção. $53 \%$ dos laboratórios brasileiros apresentaram IP menor que 2,0\%, considerado muito baixo e realizaram $44 \%$ dos exames do país. No estado de Goiás estavam cadastrados 55 laboratórios, sendo que 21 apresentaram IP $<2,0 \%$. 24 laboratórios goianos tiveram IP $>3,0 \%$ e 10 ficaram na faixa esperada (2,0\% a 2,9\%). A taxa de ASC (lesões sem diagnóstico conclusivo) foi de $4 \%$ a $5 \%$, evidenciando que os laboratórios podem aumentar a sua qualidade, para terem ainda mais diagnósticos conclusivos, positivos ou negativos (BORTOLON et al., 2012).

Em relação ao atendimento prestado às mulheres pelos profissionais da Atenção Primária à Saúde (APS) é preciso analisar o cotidiano de trabalho, que apresenta algumas barreiras para o trabalho do enfermeiro. Nas áreas da APS atuam as equipes da Estratégia Saúde da Família (ESF), onde uma das principais ações do enfermeiro é reduzir os mitos e crenças sobre a realização do exame citopatológico. É necessário aproveitar a oportunidade em que a mulher está na UBS, para realizar o exame, mas também é preciso elaborar estratégias para buscar aquelas que não procuram os serviços de saúde, utilizando-se de métodos como os mutirões à noite e nos finais de semana (MELO et al., 2012).

$O$ registro da frequência das mulheres deve ser feito com cuidado e atualizado constantemente, para conhecimento da realidade local. Todos os profissionais da equipe devem participar das atividades preventivas, para atingirem efetivamente todas as mulheres de sua região, além de contarem com suporte de pessoal especializado na coleta do material e laboratórios confiáveis para o processamento, além dos médicos para realizarem 0 tratamento, quando necessário.

A realidade, no entanto, nem sempre é favorável, levando os enfermeiros a desenvolverem atividades que compensem a ausência de outros profissionais, o que diminui a oferta de vagas para consulta e exames e compromete a qualidade do atendimento, dificultando o cumprimento das metas preconizadas pelo SUS. Dessa forma, as quatro principais ações do enfermeiro na ESF são a busca ativa das mulheres, o estabelecimento de vínculos, educação em saúde e trabalho intersetorial, com representantes da comunidade. Essas ações podem aumentar o índice de cobertura da realização do exame citopatológico e aumentar o conhecimento das mulheres sobre a sua importância, com atuação nos fatores de risco, para prevenir a ocorrência do câncer de colo uterino. Para desenvolvê-las, os enfermeiros precisam ser capacitados e qualificados, não se descuidando de sua 
formação contínua. Além disso, é preciso contar com estrutura física adequada, suprimento de materiais e organização dos processos de trabalho, para garantir a qualidade do atendimento e o cumprimento das metas (MARÇAL; GOMES, 2013).

Se as ações do enfermeiro são relevantes na prevenção do câncer de colo uterino, também são fundamentais para as mulheres sob tratamento, em função de diagnóstico positivo. É elevado o número de mulheres que só tem a doença diagnosticada em estágio avançado e nesse caso a ESF precisa oferecer, por meio do enfermeiro, cuidados paliativos, até mesmo com encaminhamento para o núcleo psicológico, que também precisa ser estruturado na região atendida. A abordagem da paciente e de seus familiares deve ser integral e resolutiva, o que só pode ser feito com amplo conhecimento da doença e dos protocolos de atendimento preconizados pelo Ministério da Saúde (PAULA et al., 2012).

No contexto das ações do enfermeiro, está a atuação junto à gestante, com abordagem oportunística ou programada durante o pré-natal, para orientar sobre os fatores de risco e a importância do exame ginecológico e coleta de material para o exame citopatológico. A gestante deve ser esclarecida sobre o fato de que esses exames não afetam a gestação e podem contribuir de maneira significativa para a sua saúde e do feto. Na prática, uma pesquisa realizada com enfermeiros em Fortaleza, estado do Ceará, revelou que raramente realizavam o exame ginecológico e coleta de material, ainda que tivessem habilitação para isso e soubessem de sua importância, sendo que 92,3\% haviam participado de treinamento sobre o a realização do exame (MANFREDI et al., 2016).

Isso mostra que o enfermeiro muitas vezes é qualificado pelo sistema público de saúde, por meio de treinamento ou em formação continuada, mas quando na sua unidade de saúde não coloca os conhecimentos obtidos totalmente em prática, prejudicando a qualidade do atendimento. A experiência profissional, fundamentada no tempo de serviço, também se reflete nessa qualidade. Ainda que o câncer de colo uterino seja raro em gestantes, a infecção pelo HPV não segue o mesmo caminho, sendo muito comum, o que demanda acompanhamento preventivo e conhecimento dos enfermeiros sobre as técnicas a serem utilizadas para os exames, para não antecipar o parto. Assim, o enfermeiro precisa atuar conforme os conhecimentos adquiridos, principalmente em grupos diferenciados, como o de gestantes ${ }^{30}$.

\section{CONCLUSÕES}

A literatura analisada mostrou que cabe ao enfermeiro executar diversas ações no contexto da APS para que as mulheres realizem o exame preventivo do câncer de colo uterino, começando pelo aproveitamento de oportunidades, quando elas vão fazer o pré-natal ou outras consultas. Nesse momento é necessário que o enfermeiro tenha os conhecimentos adequados sobre o câncer de colo uterino e outros agravos que podem ser prevenidos pelo exame citopatológico, visto que as mulheres geralmente não sabem como o teste é realizado e a sua importância.

Além dos exames oportunísticos os enfermeiros também precisam realizar a busca ativa das mulheres de sua região, principalmente aquelas sujeitas aos fatores de risco, como ser fumante, ter vida sexual ativa e múltiplos parceiros, o que aumenta as chances de serem infectadas pelo HPV. As mulheres que se consideram saudáveis muitas vezes não procuram os serviços de saúde, mas já podem estar com alguma lesão em estágio inicial, visto que elas são assintomáticas 
nessa fase. Se estiverem gestantes devem realizar o teste, para a proteção de sua saúde e do feto.

$\mathrm{Na}$ abordagem das mulheres o enfermeiro pode encontrar diversas barreiras, mas as mais difíceis de serem enfrentadas, as que demandam maior perspicácia e conhecimentos, são as que envolvem mitos e crenças sobre a saúde ginecológica. É alto o número de mulheres que acham que podem pegar alguma doença durante o exame ou que não acreditam no potencial preventivo dele. Para mudar esses padrões culturais o enfermeiro precisa formar vínculos com as comunidades e obter confiança para que suas orientações sejam seguidas.

Na APS o enfermeiro executa essas ações, mas nem sempre com resultados compensatórios, devido a fatores como a não aplicação dos conhecimentos na prática, estrutura física inadequada para a acolher as mulheres, falta de materiais para os exames, falta de recursos humanos para todo o trabalho a ser feito, distância entre a unidade de saúde e as pacientes, resistência destas à consulta e exame citopatológico, falta de retorno para repetição do exame no prazo preconizado e não seguimento do tratamento.

Alguns destes fatores estão relacionados à estrutura do sistema público de saúde, ou seja, a própria APS e outros se referem às condições culturais, sociodemográficas e econômicas das populações a serem abordados para a realização do exame preventivo. Existem diferenças regionais em relação ao atendimento no Brasil, com maior organização do trabalho em alguns locais. Essa condição resulta de ações do enfermeiro, que, ao seguir as orientações do Ministério da Saúde e contar com mais recursos, consegue oferecer atendimento com maior qualidade às usuárias.

\section{REFERÊNCIAS}

ANDRADE, M. S.; ALMEIDA, M. M. G.; ARAÚJO, T. M.; SANTOS, K. O. B. Fatores associados a não adesão ao Papanicolau entre mulheres atendidas pela Estratégia Saúde da Família em Feira de Santana, Bahia, 2010. Revista Epidemiologia e Serviços de Saúde, v. 23, n. 1, p. 111-120, 2014. Disponível em: < http://dx.doi.org/10.5123/S1679-49742014000100011> Doi: 10.5123/S167949742014000100011.

BRASIL, M. S. Controle dos cânceres do colo do útero e da mama. $2^{\text {a }}$ ed. Brasília: Ministério da Saúde, 2013.

BORTOLON, P. C.; SILVA, M. A. F.; CORRÊA, F. M.; DIAS, M. B. K.; KNUPP, V. M. A.; et al. Avaliação da qualidade dos Laboratórios de Citopatologia do colo do útero no Brasil. Revista Brasileira de Cancerologia, v. 58, n. 3, p. 435-444, 2012. Disponível em: <http://www1.inca.gov.br/rbc/n_58/v03/pdf/13_artigo_avaliacao_qualidade_laboratori os_citopatologia_colo_utero_brasil.pdf>. Acesso em: outubro de 2017.

CARVALHO, I. L. N.; NUNES, R. B.; SOUSA, I. D. B.; BATISTA, R. D. C.; SOUSA, A. S. J.; et al. Exame citopatológico: compreensão de mulheres rurais acerca da finalidade e do acesso. Revista da Rede de Enfermagem do Nordeste, v. 17, n. 5, p. 610-617, 2016. Disponível em: <http://periodicos.ufc.br/rene/article/view/6183> Acesso em: outubro de 2017. 
CASARIN, M. R.; PICCOLI, J. C. E. Educação em Saúde para prevenção do câncer de colo do útero em mulheres do município de Santo Ângelo/RS. Ciência \& Saúde Coletiva, v. 16, n. 9, p. 3925-3932, 2011. Disponível em: < http://dx.doi.org/10.1590/S1413-81232011001000029> Doi: 10.1590/S141381232011001000029 .

ETLINGER-COLONELLI, D.; LORENTE, S. Frequência das lesões detectadas no exame citopatológico, distribuídas por faixa etária, em mulheres atendidas na região do Vale do Ribeira, entre 2014 e 2015. Revista Boletim Epidemiológico Paulista, v. 13, n. 155, p. 1-10, 2016. Disponível em: $<$ http://www.saude.sp.gov.br/resources/ccd/homepage/bepa/edicao2016/edicao_155_-_novembro_2.pdf> Acesso em: outubro de 2017.

FREITAS, H. G.; SILVA, M. A.; THULER, L. C. S. Câncer do colo do Útero no estado de Mato Grosso do Sul: detecção precoce, incidência e mortalidade. Revista Brasileira de Cancerologia, v. 58, n. 3, p. 399-408, 2012. Disponível em: $<\mathrm{http}: / /$ www1.inca.gov.br/rbc/n_58/v03/pdf/09_artigo_cancer_colo_utero_estado_mat o_grosso_sul_deteccao_precoce_incidencia_mortalidade.pdf> Acesso em: outubro de 2017.

LEON, R. M.; RANZI, A. D.; FARDIN, G. S.; KEITEL, E.; BRACKMANN, R. L; et al. Imunossupressão e ocorrência de HPV em pacientes transplantados renais a partir de exame citológico urinário. Jornal Brasileiro de Patologia e Medicina Laboratorial, v. 52, n. 1, p. 25-30, 2106. Disponível em: < http://dx.doi.org/10.5935/1676-2444.20160009>. Doi: 10.5935/1676-2444.20160009.

LIMA, M. B.; PALMEIRA, M. N. A. L.; MENEZES, P. C. M.; RODRIGUES, E. S. R. C. Motivos que influenciam a não realização do exame Papanicolau segundo a percepção de mulheres. Escola Anna Nery Revista de Enfermagem, v. 17, n. 1, p. 353-369, 2017. Disponível em: <http://dx.doi.org/10.1590/S141481452009000200020 >. Doi: 10.1590/S1414-81452009000200020.

MANFREDI, R. L. S.; SABINO, L. M. M.; SILVA, D. M. A.; OLIVEIRA, E. K. F.; MARTINS, M. C. Exame Papanicolaou em gestantes: conhecimento dos enfermeiros atuantes em unidades de Atenção Primária à Saúde. Revista de Pesquisa: Cuidado é Fundamental Online, v. 8, n. 3, p. 4668-4673, 2016. Disponível em: <http://dx.doi.org/10.9789/2175-5361.2016.v8i3.4668-4673> Doi: 10.9789/21755361.2016.v8i3.4668-4673 .

MARÇAL, J. A.; GOMES, L. T. S. A prevenção do câncer de colo de útero realizada pelo enfermeiro na Estratégia Saúde da Família: revisão integrativa da literatura. Revista Eletrônico Acervo Saúde, v. 5, n. 2, p. 474-489, 2013. Disponível em: <https://www.acervosaude.com.br/doc/artigo_035.pdf>. Acesso em: outubro de 2017.

MARQUES, R. M.; SIGNORINI-FILHO, R. C.; MANCINI, S.; BARACT, N. E. C.; GONÇALVES, W.J. Diagnóstico e Tratamento. 2 ed. Manole, Baueri. 2007. 
MASCARELLO, K. C.; SILVA, N. F.; PISKE, M. T.; VIANA, K. C. G.; ZANDONADE, E. Perfil sociodemográfico e clínico de mulheres com câncer do colo do útero associado ao estadiamento inicial. Revista Brasileira de Cancerologia, v. 58, n. 3, p. 417-426, 2012. Disponível em: <http://www1.inca.gov.br/rbc/n_58/v03/pdf/11_artigo_perfil_sociodemografico_clinico mulheres_cancer_colo_utero_associado_estadiamento_inicial.pdf $>$. Acesso em: outubro de 2017.

MELO, M. C. S. C.; VILELA F.; SALIMENA, A. M. O.; SOUZA, I. E. O. O enfermeiro na prevenção do câncer do colo do útero: o cotidiano da Atenção Primária. Pós em Revista, v. 58, n. 3, 2012. Disponível em: <http://blog.newtonpaiva.br/pos/e10enferm01-o-enfermeiro-e-a-importancia-da-prevencao-do-cancer-do-colo-uterino-naatencao-a-saude-da-mulher-e-no-contexto-da-estrategia-saude-da-familia/> Acesso em: Outubro de 2017.

MELLO, C. F. Vacinação contra papilomavírus humano. Revista Einstein, v. 11, n. 4, p. 547-549, 2013. Disponível em: <http://dx.doi.org/10.1590/S167945082013000400027> Doi: 10.1590/S1679-45082013000400027.

MATIAS, L. N. A.; LOURES, L. M.; PINHEIRO, L.; CARVALHO, M. A. S. Avaliação do conhecimento de mulheres da cidade de Anápolis/Goiás sobre o exame de Papanicolau. Revista Cereus, v. 7, n. 3, p. 98-118, 2015.

NASCIMENTO, G. W. C.; PEREIRA, C. C. A.; NASCIMENTO, D. I. C.; LOURENÇO, G. C.; MACHADO, C.J. Cobertura do exame citopatológico do colo do útero no Estado de Minas Gerais, Brasil, no período entre 2000-2010: um estudo a partir dos dados do Sistema de Informação do Câncer do Colo do Útero (SISCOLO). Caderno de Saúde Coletiva, v. 23, n. 3, p. 253-260, 2015.

PAULA, C. G.; RIBEIRO, L. B.; BREDRAN, T. Atuação do enfermeiro da Atenção Básica frente ao controle do câncer uterino: revisão de literatura. Pós em Revista do Centro Universitário Newton Paiva, v. 5, p. 2013-2018, 2012. Disponível em: <http://blog.newtonpaiva.br/pos/wp-content/uploads/2013/04/PDF-E5-S33.pdf> Acesso em: outubro de 2017.

RIBEIRO, J. C.; ANDRADE, S. R. Vigilância em saúde e a cobertura de exame citopatológico do colo do útero: revisão integrativa. Revista de Literatura, v.25, n. 4, p. 53-65, 2016. Disponível em: <http://dx.doi.org/10.1590/0104$07072016005320015>$. Doi: .1590/0104-07072016005320015.

RIBEIRO, L.; BASTOS, R.R.; VIEIRA, M. T.; RIBEIRO, L. C.; TEIXEIRA, M. T. B.; et al. Rastreamento oportunístico versus perdas de oportunidade: não realização do exame de Papanicolau entre mulheres que frequentaram o pré-natal. Caderno de Saúde Pública, v. 32, n. 6, p. 1415-1528, 2016. Disponível em: <http://www.scielo.br/pdf/csp/v32n6/1678-4464-csp-32-06-e00001415.pdf> Acesso em: outubro de 2017.

RODRIGUES, B. C.; CARNEIRO, A. C. M. O.; SILVA, T. L.; SOLÁ, A. C. N.; SCHECHTMAN, N. P.; et al. Educação em saúde para a prevenção do câncer cérvico-uterino. Revista Brasileira de Educação Médica, v. 36, n. 1, p. 149-154, 
2012. Disponível em: <http://www.scielo.br/pdf/rbem/v36n1s1/v36n1s1a20.pdf > Acesso em: outubro de 2017.

SILVA, M. A. S.; TEIXEIRA, E. M. B.; FERRARI, R. A. P.; CESTARI, M. E. W.; CARDELLI, A . A. M. Fatores relacionados a não adesão à realização do exame de Papanicolau. Revista Rene, v. 16, n. 4, p. 532-539, 2015. Disponível em: $<$ http://repositorio.ufc.br/bitstream/riufc/14463/1/2015_art_massilva.pdf> Acesso em: outubro de 2017.

SILVA, S. E. D.; ARAÚJO, J. S.; CHAVES, M. O.; VASCONCELOS, E. V.; CUNHA, N. M. F.; et al. Representações sociais sobre a doença de mulheres acometidas do câncer cervico-uterino. Escola Anna Nery Revista de Enfermagem, v. 8, n. 1, p 3667-3678, $2016 . \quad$ Disponível em: <http://www.scielo.br/pdf/ean/v12n4/v12n4a12.pdf> Acesso em: outubro de 2017.

SILVEIRA, N. S. P.; VASCONCELOS, C. T. M.; NICOLAU, I. O.; ORIÁ, M. O . B.; PINHEIRO, P. N. C.; et al. Conhecimento, atitude e prática sobre o exame colpocitológico e sua relação com a idade feminina. Revista Latina-americana de Enfermagem, v. 24, p. 2699-2706, 2016. Disponível em: < Doi: 10.1590/15188345.0700.2699>.

SIQUEIRA, G. S.; OLIVEIRA, V. M. F.; BARRETO, S. M. S. S.; MENEZES, M. O.; SILVA, D. P.; et al. Citopatologia como prevenção do câncer do colo uterino. Cadernos de Graduação Ciências Biológicas e Saúde da Unit, v. 2, n. 1, p. 3749 , 2014.

<https://periodicos.set.edu.br/index.php/cadernobiologicas/article/view/1179/740> Acesso em: outubro de 2017.

SOUZA, G. D. S.; OLIVEIRA, R. A. A.; STEVANIN, A.; SOUSA, M. F.; ALMEIDA, E. C. A concepção das mulheres de Mirandópolis-São Paulo acerca do exame de Papanicolau. Revista de Enfermagem da UFSM, v. 3, n. 3, p. 470-479, 2013. Disponível em: <http://dx.doi.org/10.5902/217976929647> Doi: $10.5902 / 217976929647$.

TOMASI, E.; OLIVEIRA, T. F.; FERANDES, P. A. A. F.; THUMÉ, E.; SILVEIRA, D. S.; et al. Estrutura e processo de trabalho na prevenção do câncer de colo de útero na Atenção Básica à Saúde no Brasil: Programa de Melhoria do Acesso e da Qualidade - PMAQ. Revista Brasileira de Saúde Materno Infantil, v. 15, n. 2, p. 171-180, 2015. Disponível em: <http://dx.doi.org/10.1590/S1519$38292015000200003>$ Doi: 10.1590/S1519-38292015000200003. 